\title{
Study on prevalence of prelabour rupture of membranes and its maternal and fetal outcomes
}

\author{
Mamatha Poondru*, R. Kala, A. Kumar
}

Department of Obstetrics and Gynaecology, Government Head Quarters Hospital, Cuddalore, Tamil Nadu, India

Received: 13 September 2021

Revised: 07 October 2021

Accepted: 08 October 2021

\section{*Correspondence:}

Dr. Mamatha Poondru,

E-mail: mammu.cheraku@gmail.com

Copyright: $\odot$ the author(s), publisher and licensee Medip Academy. This is an open-access article distributed under the terms of the Creative Commons Attribution Non-Commercial License, which permits unrestricted non-commercial use, distribution, and reproduction in any medium, provided the original work is properly cited.

\section{ABSTRACT}

Background: The aim is to study the prevalence of prelabour rupture of the membranes (PROM), to identify risk factors, mode of delivery, and its maternal and fetal effects.

Methods: This was a cross-sectional study conducted in the department of obstetrics and gynaecology at Government Head Quarters Hospital, Cuddalore, Tamil Nadu, with a duration of 6months (January 2020 - June 2020). The study was conducted on 800 pregnant women between $28-42$ weeks of gestational age consecutively and those who met the inclusion and exclusion criteria were taken into study.

Results: The prevalence of PROM was 27.9\% (tPROM 24.6\% and PPROM 3.2\%). Most of the cases were primigravida (74\%). Risk factors associated with PROM were low socioeconomic state (63.2\%), urinary tract infection (UTI) (7.2\%), vaginal infections (5.8\%), and previous history of PROM (3.1\%). Most of the patients were delivered by lower segment caesarean section (LSCS) $(55.2 \%)$, normal vaginal delivery (39.9\%) and forceps delivery (4.9\%). The most common indication for LSCS was fetal distress (43.9\%). Misoprostol induction was associated with more failed induction (2 times) than syntocinon. Maternal complications were post-partum haemorrhage (PPH) (8\%), fever (6.7\%), wound infection (6.2\%), manual removal of placenta $(4.4 \%)$, and puerperal sepsis $(0.9 \%)$. Neonatal complications were neonatal intensive care unit (NICU) admissions (14\%), respiratory distress syndrome (RDS) (11\%), neonatal sepsis $(2.6 \%)$. Maternal $(54.5 \%)$ and neonatal (90\%) morbidity were more in prolonged PROM $>24$ hours.

Conclusions: Antenatal screening for genitourinary infections especially in cases of the previous history of abortions and PROM should be done. Oxytocin is the preferred method of induction over misoprostol in this study. Active management in term PROM cases can reduce the cesarean section rate.

Keywords: Pre-labour rupture of membranes, Risk factors, Mode of delivery, Induction methods, Maternal and fetal effects

\section{INTRODUCTION}

Prelabour rupture of the membranes (PROM) defines as the loss of integrity of membranes before the onset of labour, with resulting leakage of amniotic fluid and establishment of communication between the amniotic cavity, endocervical canal, and vagina. ${ }^{1}$ If it occurs after 37 weeks it is called term PROM (tPROM) and before 37 weeks it is called preterm prelabour rupture of fetal membranes (PPROM). ${ }^{2}$
The incidence of term PROM is approximately $8 \%$ and PPROM is $2-3 \%$ in Western countries like the United States and the United Kingdom. ${ }^{3}$ According to some of the Indian studies, the incidence of tPROM is approximately $5-10 \%$ and PPROM is around $2-3 \%$ of all pregnancies. ${ }^{4,5}$

Risk factors causing PROM are previous h/o PROM, lower socioeconomic status, inadequate prenatal care and nutrition, sexually transmitted infections, vaginal bleeding, and urinary tract infections. ${ }^{6}$ 
Maternal complications include chorioamnionitis, dry labour, dysfunctional and prolonged labour, increased cesarean rates, postpartum hemorrhage, puerperal sepsis, placental abruption, retained placenta, cord compression, and maternal death. ${ }^{7}$

PROM causes significant perinatal morbidities $(21.4 \%)$ and mortalities (18-20\%). ${ }^{8}$ The three causes of fetal death associated with PROM are sepsis, asphyxia, and pulmonary hypoplasia. Besides prematurity, neonatal complications include sepsis, fetal distress, intraventricular haemorrhage (IVH), RDS, necrotizing enterocolitis (NEC), jaundice, and cord compression due to oligohydramnios. ${ }^{9}$

The key in the management of PROM is an accurate gestational age, diagnosis, and the presence/absence of sepsis. ${ }^{4}$ In most instances, either it is evident from the escape of amniotic fluid from the cervix or by tests like fern pattern/litmus paper test.

The longer the time duration between the rupture of membranes and the onset of labour, the more will be the risk of chorioamnionitis. ${ }^{10}$ Evidence supports the induction of labour, as opposed to expectant management in term PROM, decreases the risk of chorioamnionitis without an increase in the cesarean delivery rate. ${ }^{11}$

In the case of PPROM, there is a controversy between expectant management and immediate delivery. Antibiotics, steroids for lung maturity and monitoring of chorioamnionitis play a role in expectant management. ${ }^{12}$

Hence, the present study was conducted to know the prevalence of prelabour rupture of membranes, and to analyze maternal and perinatal morbidity and mortality and will be useful in identifying possible preventive factors and preventive/active interventions.

\section{METHODS}

This is a cross-sectional study, conducted in the department of obstetrics and gynaecology at Government Head Quarters Hospital, Cuddalore, Tamil Nadu, which is a comprehensive emergency obstetric and newborn care services (CEMONC) centre, for a duration of 6 months (January 2020-June 2020). The sample size of 800 pregnant women who are admitted to the department was taken for study. The sample size is calculated based on previous hospital statistics and data analyzed by using statistical package for the social sciences (SPSS) version 20 .

\section{Inclusion criteria}

Gestational age of 28-42 weeks, cervical dilatation less than $3 \mathrm{~cm}$, single live pregnancy with cephalic presentation, includes both primigravida and multi gravida between 18-40 years of age.

\section{Exclusion criteria}

Multiple pregnancy, malpresentations, immune compromised cases-human immune deficiency virus (HIV) and hepatitis B surface antigen (HBsAg) positive, antepartum hemorrhage, gestational hypertension, congenital anomalies / intrauterine death, previous LSCS, gestational diabetes mellitus (GDM) and polyhydramnios.

\section{Data collection}

After institutional ethical committee approval, consecutive enrollment of pregnant women who met the inclusion and exclusion criteria were taken into the study. Informed consent was taken, and a detailed history and obstetric examination findings were noted in all patients including patients with a history of leaking per vagina.

The criteria to take subjects as PROM was: history of leaking per vagina, and lack of uterine contractions at least 1 hour from the onset of PROM.

Confirmation of PROM was done by draining fluid from the cervix or pooling in the posterior fornix on a sterile speculum examination, and with a fern test. Doubtful cases of leaking PV were not taken as PROM. After assessing the colour and odour of liquor, bishop scoring was done.

Gestational age was confirmed with early ultrasonography, obstetric ultrasonography was done to assess gestational age (GA), amniotic fluid index (AFI), presentation, and biophysical profile. Prophylactic intravenous antibiotic injection of ampicillin $1 \mathrm{gm} 6^{\text {th }}$ hourly was administered in all cases of PROM. In preterm PROM, corticosteroids were given for lung maturity. In late-preterm PROM $\left(34^{+0}\right.$ to $36^{+6}$ weeks $)$ with the latent phase of labour, waited for spontaneous progression of labour and per vaginal examinations were reduced. In term PROM, the mode of delivery was decided based on bishop score, AFI, and CTG. Severe oligohydramnios $(<5 \mathrm{~cm}$ AFI) and non-reactive CTG cases were decided to emergency LSCS.

Cases with the favourable cervix (bishop score $\geq 6$ ) and adequate liquor waited for spontaneous progression labour. Cases with the favourable cervix and reduced liquor (AFI- 6 to $8 \mathrm{~cm}$ ) were selected for syntocinon induction and an unfavorable cervix with adequate liquor was selected for misoprostol (25 micrograms, sublingual) induction. The progression of labour, signs of chorioamnionitis, fetal heart rate were monitored in PROM cases.

The time interval from PROM to delivery and induction to delivery was noted. After delivery, weight and Apgar score of the newborn were noted and the mother is monitored for complications like PPH and retained placenta. Mother and baby were further monitored for any complications until discharge from the hospital in cases of PROM. 


\section{RESULTS}

The present study was performed on 800 pregnant women who met inclusion and exclusion criteria. The following statistical results are analyzed for PROM cases.

The prevalence of total PROM among 800 women was $27.9 \%$ (term PROM was $24.6 \%$ and preterm PROM was $3.3 \%$ ). Among PROM cases, 197 cases were at term i.e. $88.3 \%$ and 26 cases were at preterm i.e. $11.7 \%$ (Table 1).

74\% PROM cases were primigravida, $19.3 \%$ were multigravida and $6.7 \%$ were nullipara (Figure 1).

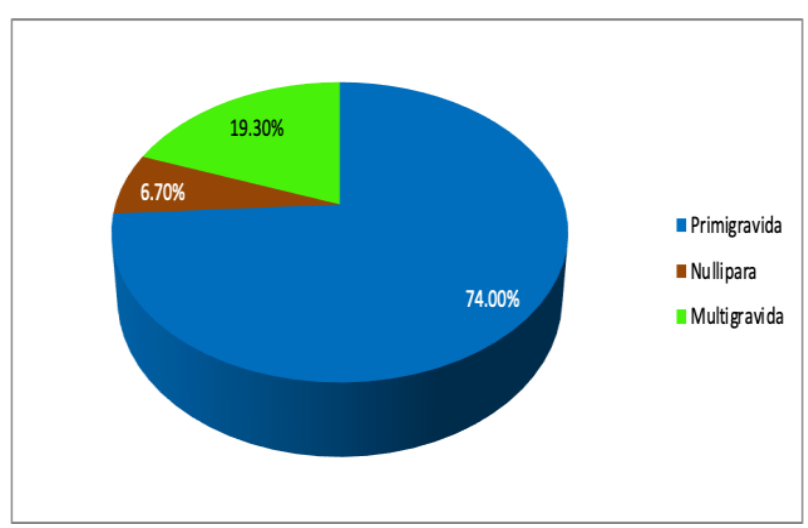

Figure 1: Distribution of PROM based on the obstetric score $(n=223)$.

Most of the PROM cases belong to low socio-economic status (63.2\%) and $36.8 \%$ of cases belong to middle socioeconomic status (Figure 2).
In this study $78 \%$ of cases had unknown cause, $7.2 \%$ associated with UTI, 5.8\% associated with local vaginal infections, $3.1 \%$ hada history of recent coitus, $3.1 \%$ had a previous history of PROM and $2.2 \%$ had a history of vaginal bleeding in the first trimester (Figure 3 ).

$55.2 \%$ of PROM cases had delivered by the LSCS, $39.9 \%$ of cases had a normal vaginal delivery and $4.9 \%$ of cases had delivered by using forceps (Figure 4 ).

Table 1: Distribution of PROM among all the delivery cases $(n=800)$.

\begin{tabular}{|lllll|}
\hline PROM & Term & Preterm & Total & Percent \\
\hline Yes & 197 & 26 & 223 & 27.9 \\
\hline No & 556 & 21 & 577 & 72.1 \\
\hline Total & & & 800 & 100.0 \\
\hline
\end{tabular}

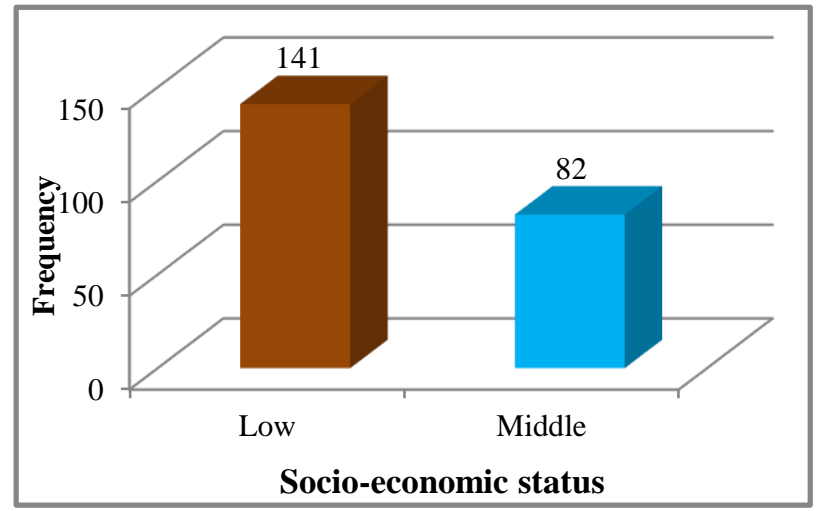

Figure 2: Distribution of PROM based on the socioeconomic status $(n=223)$.

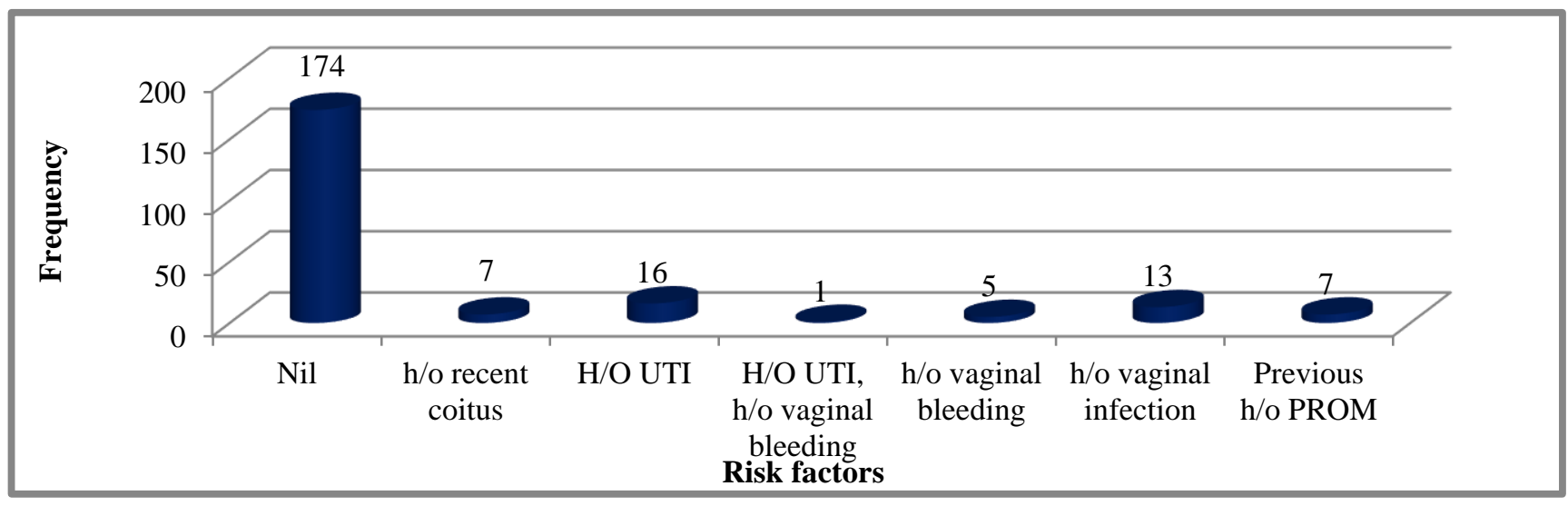

Figure 3: Distribution of PROM cases based on the risk factors $(n=223)$.

In total induction deliveries, $52 \%$ delivered vaginally and $47.9 \%$ by LSCS. Most of the misoprostol induced cases underwent emergency LSCS $(64.7 \%)$ than vaginal delivery $(35.3 \%)$. In syntocinon induced patients- vaginal delivery $(54.7 \%)$ more than LSCS (45.3\%) (Table 2).

Indication for LSCS without any induction was severe oligohydramnios (48\%). In both the methods of induction fetal distress (43.9\%) was the most common indication for LSCS. Failed induction and MSL were more common in miso induction and fetal distress was more in synto induction. Failed induction 2 times more in misoprostol induction than syntocinon induction (Table 3 ).

In this study maternal complications were $8 \%$ of $\mathrm{PPH}$, $6.7 \%$ fever, $6.3 \%$ wound infection, $4.4 \%$ manual removal 
of placenta, $0.9 \%$ puerperal sepsis and $0.44 \%$ abruption and uterine inversion respectively (Table 4).

In this study, $14.7 \%$ of babies admitted in NICU, $11.2 \%$ developed RDS, $2.69 \%$ developed neonatal sepsis and $0.4 \%$ developed birth asphyxia, $13.4 \%$ of babies had neonatal jaundice and $0.4 \%$ had convulsions (Figure 5).

In this study, maternal and neonatal morbidity increased as the PROM delivery interval increased. $10.3 \%$ of maternal morbidity was observed within 12 hours of PROM, 40.2\% and $54.5 \%$ of morbidity was observed between $12-24$ hours of PROM and $>24$ hours respectively. $31.9 \%$ neonatal morbidity observed in $<12$ hours of PROM, $55.8 \%$ and $90.0 \%$ of neonatal morbidity was observed between 12-24 hours and $>24$ hours of PROM respectively (Table 5).

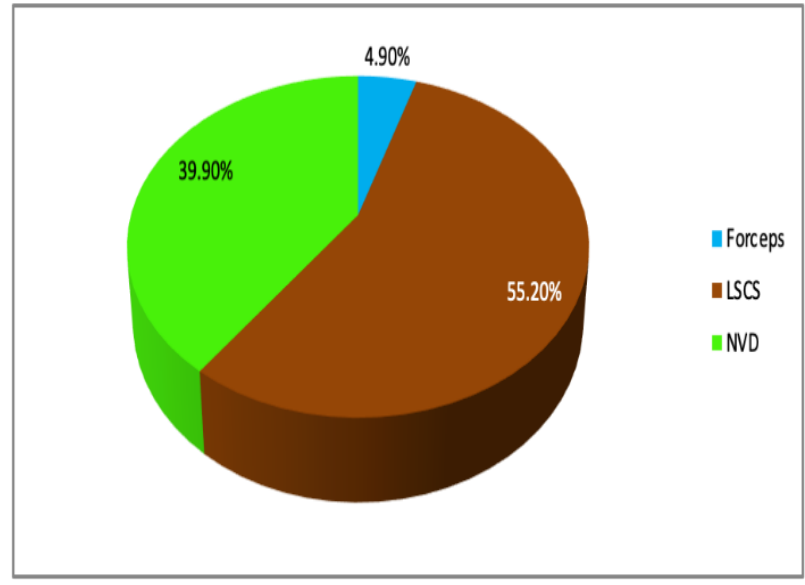

Figure 4: Distribution of PROM cases based on the mode of delivery $(n=223)$.

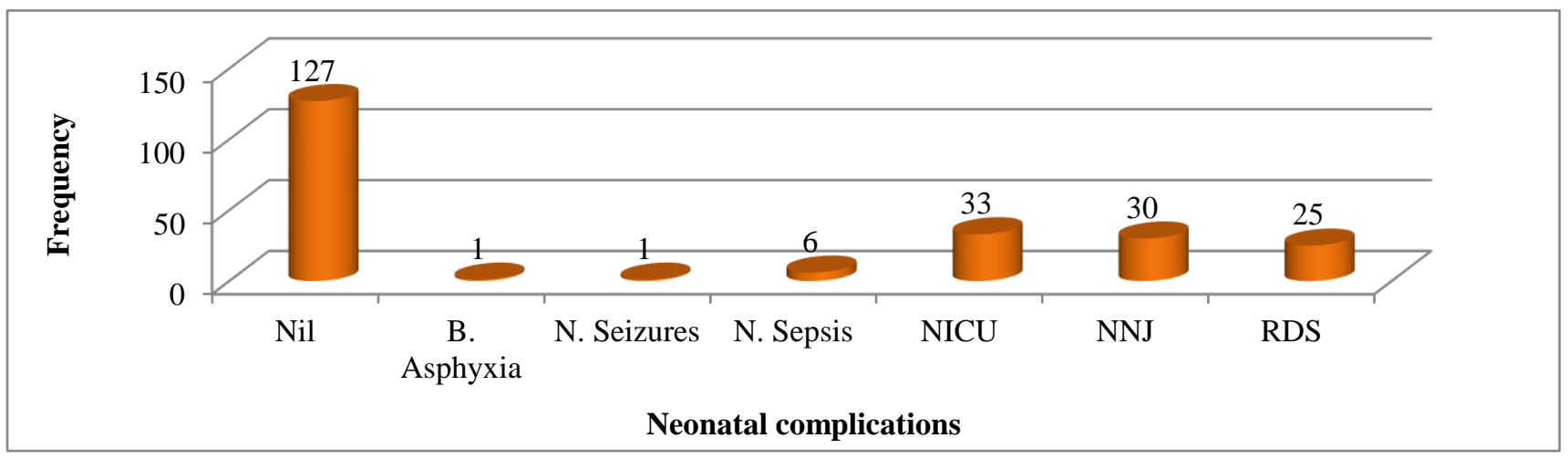

Figure 5: Distribution of neonatal complications in PROM $(n=223)$.

Table 2: The relation between mode of induction and mode of delivery.

\begin{tabular}{|llll|}
\hline Mode of induction & MOD $(\%)$ & Vaginal delivery & Total $(\%)$ \\
\hline Miso & LSCS & $6(35.3)$ & $17(100.0)$ \\
\hline Synto & $11(64.7)$ & $58(54.7)$ & $106(100.0)$ \\
\hline Total & $48(45.3)$ & $64(52.0)$ & $123(100.0)$ \\
\hline
\end{tabular}

Table 3: Distribution of cases among LSCS in PROM (n=123).

\begin{tabular}{|llllll|}
\hline $\begin{array}{l}\text { S. } \\
\text { no. }\end{array}$ & Indication & Without induction (\%) & $\begin{array}{l}\text { Induction (\%) } \\
\text { Synto }\end{array}$ & Miso & Total (\%) \\
\hline $\mathbf{1}$ & Fetal distress & $24(37.5)$ & $26(54)$ & $4(36.3)$ & $54(43.9)$ \\
\hline $\mathbf{2}$ & Severe oligohydramnios & $31(48)$ & - & - & $31(25.2)$ \\
\hline $\mathbf{3}$ & CPD & $6(9.3)$ & - & - & $6(4.9)$ \\
\hline $\mathbf{4}$ & Failure to progress & - & $10(20)$ & $2(18)$ & $12(9.8)$ \\
\hline $\mathbf{5}$ & MSL & $3(4.6)$ & $7(14)$ & $2(18)$ & $12(9.8)$ \\
\hline $\mathbf{6}$ & Failed induction & - & $5(10.4)$ & $3(27.2)$ & $8(6.5)$ \\
\hline & Total & 64 & 48 & 11 & 123 \\
\hline
\end{tabular}

Table 4: Distribution of maternal complications in PROM (n=223).

\begin{tabular}{|lllc|}
\hline S. no. & Maternal complications & Frequency & Percentage \\
\hline $\mathbf{1}$ & Abruption & 1 & 0.4 \\
\hline $\mathbf{2}$ & Fever & 15 & 6.7 \\
\hline
\end{tabular}

Continued 


\begin{tabular}{|llll|}
\hline S. no. & Maternal complications & Frequency & Percentage \\
\hline $\mathbf{3}$ & PPH & 18 & 8.1 \\
\hline $\mathbf{4}$ & Wound infection & 14 & 6.3 \\
\hline $\mathbf{5}$ & Manual removal of placenta & 10 & 4.4 \\
\hline $\mathbf{6}$ & Uterine inversion & 1 & 0.4 \\
\hline $\mathbf{7}$ & Puerperal sepsis & 2 & 0.9 \\
\hline $\mathbf{8}$ & Nil & 172 & 77.1 \\
\hline
\end{tabular}

Table 5: Maternal and neonatal morbidity in relation to PDI.

\begin{tabular}{|llll|}
\hline PDI in hours & Total no. & No. of maternal complications (\%) & No. of neonatal complications (\%) \\
\hline $\mathbf{1 2}$ & 135 & $14(10.3)$ & $43(31.9)$ \\
\hline $\mathbf{1 2}$ to $\mathbf{2 4}$ & 77 & $31(40.2)$ & $43(55.8)$ \\
\hline$>\mathbf{2 4}$ & 11 & $6(54.5)$ & $10(90.9)$ \\
\hline
\end{tabular}

\section{DISCUSSION}

The prevalence of PROM in this study is $27.9 \%$, among them, term PROM prevalence is $24.6 \%$ (197/800) and preterm PROM prevalence is $3.25 \%$ (26/800).

PPROM prevalence is similar to Hackenhaar et al $3.1 \%$, and Canavan et al 3\%.13,14 Other studies which showed more PPROM prevalence are Addisu et al $13.7 \%$, Byonanuwe et al $7.5 \%$, and studies that showed less PPROM prevalence are Mohan et al $2.2 \%$ may be due to better screening for local infection and good antenatal care. ${ }^{5,15,16}$

Term PROM prevalence is much higher than Segni et al $17.6 \%$, Hexia Xia et al $12.5 \%$, and Liu et al $19.5 \% .^{8,17,18}$ The high rate of term PROM prevalence might be due to the institute being a referral center to all surrounding hospitals in the district, ineffective screening of genitourinary infections, low socioeconomic status groups, unavailability of private hospitals due to the COVID-19 pandemic.

In this study, $74 \%$ of cases are primigravida, $6.7 \%$ are nullipara, and $19.3 \%$ are multigravida. This is comparable to Endale et al where $69.7 \%$ primigravida, Amulya et al $80 \%$ primigravida, and the results are in contrast to Dars et al where $17 \%$ primigravida and $83 \%$ were multigravida. ${ }^{19,20,21}$ According to Aktar et al, chances of increased sexual activity and increased genital infections are most common among primigravida. ${ }^{22}$

In this study, $63.2 \%$ of PROM cases are in the low socioeconomic status groups and $36.8 \%$ are in the middle socioeconomic groups. This was comparable with the studies conducted by Pandey et al which was $61 \%$ and $39 \%$, Mohan $^{5}$ et al 55.2\% and 29.6\%.5,23 PROM in the low socioeconomic status groups is associated with factors like malnutrition, poor hygiene, overexertion, recurrent genitourinary infections, and decreased antibacterial activity in amniotic fluid.

PROM was most commonly associated with UTI (7.2\%), local vaginal infections $(5.8 \%)$, nulliparous $(6.7 \%)$, previous history of PROM (3.1\%), history of recent coitus $(3.1 \%)$, and history of vaginal bleeding $(2.2 \%)$. This is comparable with Patil's 6\% UTI, 6\% previous PROM, $10 \%$ recent coitus, Boskabadi et al showed $7.2 \%$ UTI, $8.9 \%$ previous PROM. ${ }^{6,7}$ UTI is the potential reservoir of bacteria that cross to the vagina and ascend through the cervix to the membranes, where they cause local inflammation, and proteolytic enzymes produced by bacteria cause the weakening of membranes.

In the present study, $55.2 \%$ of cases underwent LSCS, $39.9 \%$ of cases had NVD, and $4.9 \%$ of cases were delivered by forceps. Cesarean section rate is higher in this study when compared with other studies, Devi et al showed $45.2 \%, 7.6 \%$, and $42.3 \%$, Kadikar et al $31 \%, 57 \%$, and $12 \%$ respectively. ${ }^{24,25}$ The result is less compared to Charles et al, where $58.7 \%$ were LSCS. ${ }^{26}$ The higher rate of LSCS in this study is mainly due to more number of cases that underwent direct LSCS due to severe oligohydramnios (25.2\%), CPD (4.9\%), fetal distress, and because this institution is a referral center, many of the cases who required LSCS will be referred here.

Other indications of LSCS in this study are fetal distress (43.9\%), followed by failure to progress $(9.8 \%)$, MSL $(9.8 \%)$, and failed induction $(6.5 \%)$. According to Hofmeyr et al reduced fluid around the baby increased the chances of cord compression, which can reduce the supply of nutrients and oxygen. ${ }^{27}$ Piazze et al indicates that the presence of oligohydramnios in premature rupture of membranes is related to shorter latency compared to without oligohydramnios. ${ }^{28}$ Ademilbishi et al showed the most common indication for LSCS was fetal distress. ${ }^{29}$ Mukharya et al reported $72.7 \%$ in the expectantly, $41.3 \%$ in the actively managed group underwent LSCS due to fetal distress. ${ }^{4}$

Among induced patients $(n=123) \quad 52.3 \%$ delivered vaginally, and $47.9 \%$ underwent LSCS. Among induction methods (misoprostol and syntocinon), syntocinon induced patients delivered more vaginally (58 out of 106) than LSCS, and misoprostol induced patients delivered more by LSCS (11 out of 17). In both methods, fetal distress is the most common indication for LSCS, with 
$54 \%$ in syntocinon and $36.3 \%$ in misoprostol induction respectively. Syntocinon induction is associated with less failed induction and MSL than misoprostol. Failed induction is 2 times more in misoprostol than syntocinon. According to American college of obstetricians and gynecologists (ACOG) guidelines, oxytocin is the firstline of labour induction in term PROM than prostaglandins. ${ }^{30}$ Studies related to induction method are Mbalika et al showed $81 \%$ and $83 \%$ vaginal deliveries in misoprostol and oxytocin-induction, and Kulhan et al reported $52.7 \%$ and $35.7 \%$ rates of LSCS in dinoprostone and oxytocin group respectively. ${ }^{31,32}$ Poornima et al reported CS and operative vaginal deliveries more in the induced group. ${ }^{33}$

Maternal complications in this study are postpartum hemorrhage $(8 \%)$, fever $(6.7 \%)$, wound infections $(6.27 \%)$, manual removal of placenta $(4.4 \%)$, puerperal sepsis $(0.85)$ and rarely abruption and uterine inversion $(0.4 \%, 0.4 \%)$. According to Kayiga et al reported that all infection-related postpartum morbidities were more after cesarean, rather than vaginal delivery. ${ }^{34}$ Studies with similar results are Surayapalem et al which showed $8 \%$ fever and $1 \%$ puerperal sepsis, and studies that show more results than this study are Mukarya et al where fever $12 \%$ and $18 \%, \mathrm{PPH} 3 \%$ and $7 \%$ in active management and expectant management group respectively, Amulya et al reported $9.6 \%$ fever, $3.3 \%$, PPH $1.66 \%$ and puerperal sepsis $1.66 \%$, and Mohan et al showed $4.1 \% \mathrm{PPH}, 2.3 \%$ abruption, and $14.6 \%$ sepsis. $^{4,5,20,35}$

In this study, maternal morbidity is more when the PROM delivery interval increased. $10.3 \%$ in $<12$ hours, $40 \%$ in between 12 to 24 hours, and $54.5 \%$ in $>24$ hours. Padmaja et al reported $1 \%, 5 \%$, and $20 \%$ respectively, Khade et al reported $1 \%, 2 \%$, and $13 \%$ respectively. ${ }^{36,37}$ Prophylactic antibiotics and immediate induction in term cases decreased the maternal morbidity in this study.

Neonatal complications in this study are NICU admissions (14.7\%), RDS (11.2\%), neonatal jaundice (13.4\%), neonatal sepsis $(2.6 \%), 0.4 \%$ birth asphyxia, and neonatal seizures respectively. These results are less compared to Surayapalem et al reported birth asphyxia $14 \%$, septicemia $4 \%$, convulsions 3\%, Akter et al showed $6.7 \%$ neonatal sepsis, $22 \%$ neonatal jaundice, and $2.2 \%$ birth asphyxia, $11.1 \% \mathrm{RDS}^{35,38}$ This variation may be due to the use of prophylactic antibiotics and early delivery. These results are more compared to Surekha et al which showed $4.4 \%$ RDS, $4.7 \%$ hyperbilirubinemia, $6.58 \%$ sepsis, and Mukharya et al showed $11 \%$ and $15 \%$ of NICU admission in expectant management and active management groups respectively. ${ }^{4,5}$

Neonatal morbidity in relation to PROM to the delivery time interval in this study is $31.85 \%$ within 12 hours, $55.8 \%$ between 12 to 24 hours, and $90.9 \%$ after 24 hours. These results are much higher than Padmaja et al which reported $10 \%, 30 \%$, and $25 \%$ respectively. ${ }^{36}$

\section{Limitations}

Duration of time could have been increased to calculate the precise prevalence. Inclusion of medical disorders of pregnancy like gestational hypertension, GDM and previous LSCS cases would have changed the prevalence of PROM in this study. Having a tertiary care institute could remove the need for referral to other centers for managing preterm babies.

\section{CONCLUSION}

PROM is a common complication of pregnancy. It can lead to increased operative deliveries, maternal and neonatal complications. Low socio-economic group patients are associated with PROM, which can be reduced by government health programs by providing adequate nutrition. PROM can be avoided by providing personal hygiene education by village health workers. PROM is prevalent in the primigravida and nullipara groups. These can be prevented by creating awareness regarding the importance of good antenatal check-ups. Early induction showed more vaginal deliveries than LSCS in this study. Both maternal and neonatal morbidities were more with increased PROM delivery interval time.

\section{Recommendations}

Antenatal screening for genitourinary infections especially in cases of the previous history of abortions and PROM should be done. IV prophylactic antibiotics, timely intervention, and careful monitoring can prevent infectionrelated morbidities. Oxytocin is the preferred method of induction than misoprostol. Active management in term PROM cases can reduce the cesarean section rate.

Funding: No funding sources Conflict of interest: None declared

Ethical approval: The study was approved by the Institutional Ethics Committee

\section{REFERENCES}

1. Larranaga-Azcarate C, Campo-Molina G, PerezRodriguez AF. Dinoprostone vaginal slow-release system compared to expectant management in the active treatment of premature rupture of the membranes at term: impact on maternal and fetal outcomes. Acta Obstetricia et Gynecologica Scandinavica. 2008;87(2):195-200.

2. Modena AB, Kaihura C, Fieni S. Prelabour rupture of the membranes: recent evidence. Acta Biomedica. 2004;75:5-10.

3. Prelabor Rupture of Membranes: ACOG Practice Bulletin, Number 217. Obstet Gynecol. 2020;135(3):80-97.

4. Mukharya J, Mukharya S. Comparative study of fetal and maternal outcomes of prelabour rupture of membranes at term. Int J Reprod Contracept Obstet Gynecol. 2017;6(1). 
5. Mohan SS, Thippeveeranna C, Singh NN, Singh LR. Analysis of risk factors, maternal and fetal outcome of spontaneous preterm premature rupture of membranes: a cross-sectional study. Int J Reprod Contracept Obstet Gynecol. 2017;6(9).

6. Boskabadi H, Hamidi MZ, Maamouri G, Najafi A. Frequency of Maternal Risk Factors and Neonatal Complications of Premature Rupture of Membranes. J Babol University Med Sci. 2016;18(10).

7. Patil S, Patil V. Maternal and Foetal Outcome in Premature Rupture of Membranes. IOSR J Dent Med Sci. 2014;13(12).

8. Jing L, Zhi-Chun F, Jing W. The Incidence rate of premature rupture of membranes and its influence on fetal-neonatal health: a report from mainland China. J Trop Pediatr. 2010;56:36-42.

9. Khashogi TY. The outcome of pregnancies with preterm premature rupture of membranes. Saudi Med J. 2004;25(12):1957-61.

10. Noor S, Nazar AF, Bashir R, Suitana R. Prevalence of PROM and its outcome. J Ayub Med Coll Abbottabad Pak. 2007;19(4):14-7.

11. Akyol D, Mungan T, Unsak A. Pre labour rupture of membranes at term-no advantage of delaying induction for 24 hours. Aust N Zeal Obstet Gynecol. 1999;39(3):291-5.

12. Aris IM, Logan S, Lim C, Choolani M, Bhattacharya S. Preterm prelabour rupture of membranes: a retrospective cohort study of association with adverse outcome in the subsequent pregnancy. BJOG. 2016;124(11):1698-707.

13. Hackenhaar AA, Albernaz EP. Preterm premature rupture of the fetal membranes: association with sociodemographic factors and maternal genitourinary infections. J Pediatr. 2014;90(2).

14. Canavan TP, Simhan HN. An evidence-based approach to the evaluation and treatment of premature rupture of membranes: Part II. Obstet Gynecol Surv. 2004;59(9).

15. Addisu D, Melkie A, Biru S. Prevalence of Preterm Premature Rupture of Membrane and Its Associated Factors among Pregnant Women Admitted in Debre Tabor General Hospital, North West Ethiopia: Institutional-Based Cross-Sectional Study. Obstet Gynecol Int. 2020;4034680.

16. Byonanuwe S, Nzabandora E, Nyongozi B. Predictors of Premature Rupture of Membranes among Pregnant Women in Rural Uganda: A Cross-Sectional Study at a Tertiary Teaching Hospital. Int J Reprod Med. 2020;1862786.

17. Segni H, Diriba TD, Yesuf EA. Incidence, Maternal and Perinatal Outcome of Premature Rupture of Fetal Membrane Cases in Jimma University Teaching Hospital, South West Ethiopia. EC Gynaecol. 2017;5(4).

18. Hexia Xia, Li X, Li X, Liang H, Xu H. The clinical management and outcome of term premature rupture of the membrane in East China: results from a retrospective multicenter study. Int J Clin Exp Med. 2015;8(4).
19. Tigist E, Netsanet F, Desta G. Maternal and fetal outcome in term premature rupture of membranes. World J Emerg Med. 2016;7(2):147-52.

20. Amulya MN, Ashwini MS. The maternal outcome in term premature rupture of membranes. Int J Reprod Contracept Obstet Gynecol. 2019;8(2):576-79.

21. Dars S, Malik S, Samreen I, Kazi RA. Maternal morbidity and perinatal outcome in preterm premature rupture of membranes before 37 weeks gestation. Pak J Med Sci. 2014;30(3).

22. Aktar MS, Degan JS, Aktar UA, Sharma D. PROM: Study of 300 cases and review of the literature. J Obstet Gynecol India. 1980;30.

23. Pandey S, Dave A, Bandi S. Maternal and Fetal Outcome in case of PROM. J Obstet Gynecol India. 2000;50(1):63-5.

24. Devi A, Rani R. Premature rupture of membranes - A clinical study. Journal of Obstet and Gynaecol of India. 1996;8:46-63.

25. Kadikar GK, Gandhi MR, Damani SK. A Study of Feto-Maternal Outcome in Cases of Premature Rupture of Membrane. Int J Scientific Res. 2014;3(3).

26. Pasquier JC, Rabilloud M, Picaud JC, Ecochard R, Claris $\mathrm{O}$, Gaucherand $\mathrm{P}$, et al. A prospective population-based study of 598 cases of PPROM between 24 and 34 weeks' gestation: description, management, and mortality (DOMINOS cohort). Eur J Obstet Gynecol Reprod Biol. 2005;121(2):164-70.

27. Hofmeyr GJ, Eke AC, Lawrie TA. Amnioinfusion for third trimester preterm premature rupture of membranes. Cochrane Database Syst Rev. 2014;2014(3):CD000942.

28. Piazze J, Anceschi MM, Cerekja A, Brunelli R, Meloni P, Marzano S, Cosmi E. Validity of amniotic fluid index in preterm rupture of membranes. J Perinat Med. 2007;35(5):394-8.

29. Ibishi VA, Isjanovska RD. Prelabour Rupture of Membranes: Mode of Delivery and Outcome. Open Access Maced J Med Sci. 2015;3(2):237-40.

30. ACOG Committee on Practice Bulletins-Obstetrics. ACOG Practice Bulletin No. 80: premature rupture of membranes. Clinical management guidelines for obstetrician-gynecologists. Obstet Gynecol. 2007;109(4):1007-19.

31. Mbaluka CM, Kamau K, Karanja JG, Mugo N. Effectiveness and safety of 2-hourly $20 \mathrm{mcg}$ oral misoprostol solution compared to standard intravenous oxytocin in labour induction due to prelabour rupture of membranes at term: a randomised clinical trial at Kenyatta national hospital. East Afr Med J. 2014;91(9):303-10.

32. Kulhan NG, Kulhan M. Labor induction in term nulliparous women with premature rupture of membranes: oxytocin versus dinoprostone. Arch Med Sci. 2019;15(4):896-901

33. Poornima B, Dharma Reddy DB. Premature Rupture of Membranes at Term: Immediate Induction With PGE(2) Gel Compared With Delayed Induction With Oxytocin. J Obstet Gynaecol India. 2011;61(5):516-8. 
34. Kayiga H, Lester F, Amuge PM, Byamugisha J, Autry AM. Impact of mode of delivery on pregnancy outcomes in women with premature rupture of membranes after 28 weeks of gestation in a lowresource setting: A prospective cohort study. PLoS One. 2018;13(1):e0190388.

35. Sailaja S, Vijayalakshmi C, Bhuvaneswari S. A study on maternal and perinatal outcome in premature rupture of membranes at term. Int $\mathbf{J}$ Reprod Contracept Obstet Gynecol. 2017;6(12):5368-72.

36. Padmaja J, Swarupa K. Maternal and perinatal outcome in premature rupture of membranes at term pregnancy. Int Arch Integ Med. 2018;5(4):87-91.
37. Khade SA, Bava AK. Preterm premature rupture of membranes: maternal and perinatal outcome. Int $\mathbf{J}$ Reprod Contracept Obstet Gynecol. 2018;7(11).

38. Akter S, Akter R, Rashid M. Preterm Prelabour Rupture of the Membrane \& Feto-Maternal outcome: an Observational Study. J Bangladesh Coll Phys Surg. 2010;28(1).

Cite this article as: Poondru M, Kala R, Kumar A. Study on prevalence of prelabour rupture of membranes and its maternal and fetal outcomes. Int $\mathbf{J}$ Reprod Contracept Obstet Gynecol 2021;10:4163-70. 